\title{
Pemberdayaan Ekonomi Desa Pagaruyung Dalam Upaya Optimalisasi Produksi Produk Olahan Nanas Serta Manajemen Limbah Pasca Produksi
}

\author{
Dwi Annisa Fithry ${ }^{1}$, Nidya Vitriana2 ${ }^{2}$, M Nurdin ${ }^{3}$ \\ ${ }^{1}$ Prodi Teknik Kimia,Fakultas Teknik, Universitas Muhammadiyah Riau \\ ${ }^{2}$ Prodi Akuntansi, Fakultas Ekonomi dan Bisnis, Universitas Muhammadiyah Riau \\ ${ }^{2}$ Prodi Teknik Mesin, Fakultas Teknik, Universitas Muhammadiyah Riau \\ email: Dwiannisa@umri.ac.id
}

\begin{abstract}
Pineapple is one of the fruit plants that are widely cultivated in tropical and subtropical areas. One of the areas in Tapung District, Kampar Regency, Riau Province with a large number of pineapple producers is Pagaruyung Village. Pineapple farmers immediately sell their harvests without processing, but since the COVID-19 pandemic, marketing their pineapple crops has begun to be difficult to market. Data collection methods are carried out by means of analysis and surveys of partner locations. With this dedication, it is hoped that the pineapple farmers in Pagaruyung Village can overcome the marketing method for pineapple harvests, so that they can revive the Pagaruyung Village economy.
\end{abstract}

Keywords: Economic empowerment, packaging and marketing, pineapple farmer

\begin{abstract}
Abstrak
Nanas merupakan salah satu tanaman buah yang banyak dibudidayakan di daerah tropis dan subtropis. Salah satu daerah di Kecamatan Tapung, Kabupaten Kampar, Provinsi Riau dengan penghasil buah nanas yang banyak adalah Desa Pagaruyung. Petani nanas lansung menjualkan hasil panen mereka tanpa pengolahan, namun semenjak masa pandemi covid 19 memasarkan hasil panen nanas mulai sulit dipasarkan. Metode pengumpulan data dilakukan dengan cara analisis dan survey lokasi mitra. Dengan pengabdian ini diharapkan para petani nanas Desa Pagaruyung dapat mengatasi cara pemasaran hasil panen nanas, sehingga dapat membangkitkan kembali perekonomian Desa Pagaruyung.
\end{abstract}

Kata Kunci: Pemberdayaan ekonomi, pengemasan dan pemasaran, kelompok tani nanas

\section{PENDAHULUAN}

Nanas merupakan salah satu tanaman buah yang banyak dibudidayakan di daerah tropis dan subtropis. Tanaman ini mempunyai banyak manfaat terutama pada buahnya. (Haifa Victoria, 2018: 1). Menurut Lingga (dalam Tri Lestari, 2020: 54) Nanas juga merupakan buah-buahan yang kaya akan manfaat. Konsumsi nanas dengan rutin membuat seluruh sel dan sitoplasma terlindungi dari dampak buruk radikal bebas. Buah yang kaya akan manfaatnya ini banyak ditanam oleh para petani lokal.
Salah satu daerah di Kecamatan Tapung, Kabupaten Kampar, Provinsi Riau dengan penghasil buah nanas yang banyak adalah Desa Pagaruyung. Desa Pagaruyung merupakan desa yang mayoritas mata pencarian penduduknya dari hasil perkebunan. Potensi agroklimat dan ketersediaan lahan di Desa Pagaruyung akan mendukung dalam pengembangan budidaya nanas, sehingga Desa Pagaruyung mempunyai peluang yang besar untuk mensuplai kebutuhan nanas yang lebih besar di pasar global. 
Para petani nanas di Desa Pagaruyung tergabung kedalam Kelompok Tani Nanas. Kelompok Tani Nanas merupakan gabungan beberapa kelompok petani nanas, dengan kegiatan yaitu mengelola perkebunan nanas yang kemudian hasil perkebunan dijual kepada tengkulak. Hingga saat ini Kelompok Tani Nanas desa Pagaruyung masih mengandalkan tengkulak sebagai penampung hasil panen mereka. Semenjak masa pandemi covid 19 hasil panen buah nanas mulai sulit dipasarkan karena beberapa tengkulak membatasi jumlah hasil panen yang mereka tampung. Oleh karena itu perlu adanya implementasi pengolahan hasil perkebunan nanas menjadi suatu produk yang memiliki nilai jual agar hasil perkebunan dapat terus dipasarkan dan meningkatkan perekonomian.

\section{METODE PENGABDIAN}

Metode pengumpulan data dilakukan dengan cara analisis dan survey lokasi mitra. Berdasarkan hasil analisis Tim Kuliah Kerja Nyata (KKN) kelompok 13 di Desa Pagaruyung terkait permasalahn mitra maka, dapat disusun teknik pelaksanaan program kerja secara Theoritical dan Practical yang dilakukan secara "blanded" yaitu virtual-digital, online dan offline dengan memperhatikan protokol kesehatan

1) Metode sosialisasi dan tanya jawab melalui google meet ataupun zoom meeting

Dimana dalam hal ini beberapa usulan program kerja akan disampaikan secara teori yaitu seperti pemberian materi secara teknis, kiat-kiat dan solusi, yang dilakukan melalui virtual yaitu googlemeet ataupun zoom meeting.

2) demonstrasi produk dalam bentuk vidio yang disebarkan melalui whatsApp

Metode ini dilakukan dengan menyebarkan vidio praktek olahan produk nanas dengan bervariasi olahan, praktek bagaimana packaging yang bagus untuk menarik perhatian konsumen, serta praktek pengolahan limbah nanas menjadi pupuk tanaman.

\section{3) Praktek langsung dengan} kelompok tani nanas

Praktek langsung dimana warga Desa Pagaruyung dapat terlibat langsung dalam program kerja yang kami usulkan, sehingga sumber daya Desa Pagaruyung dapat lebih dioptimalkan lagi dan potensi Desa lebih produktif lagi. Pelaksanaan kegiatan dilakukan berdasarkan protokol kesehatan, antar lain dengan membatasi jumlah peserta dalam setiap program

\section{Rencana Kegiatan}

1) Sosialisasi dan pelatihan teknik produksi olahan nanas

Kegiatan ini diawali dengan penyampaian materi dasar tentang sistem produksi produk olahan nanas lokal berkualitas dengan materi yang disusun secara sederhana untuk memudahkan mitra untuk memahaminya. Selanjutnya praktek pengolahan nanas menjadi produk yaitu berupa selai nanas, sirup nanas, dan pudding nanas. Dengan tujuan untuk meningkatkan produktifitas petani nanas, agar buah nanas dapat dijual dalam bentuk produk olahan.

2) Pengolahan limbah nanas menjadi pupuk

Mengolah kulit nanas menjadi pupuk tanaman dengan campuran bahanbahan lainnya untuk membuat pupuk, kemudian didiamkan selama beberapa waktu. Tujuannya untuk mengurangi limbah yang dapat mencemari lingkungan, mafaat limbah nanas sebagai pupuk organic dang mengurangi penggunaan pupuk kimia. Kegiatan ini dilakukan bersama Kelompok tani nanas, ibu-ibu PKK, dan warga desa 
3) Manajemen pemasaran dan kemasan produk

Pembuatan konsep pemasaran yaitu dengan cara pelatihan membuat web market place, pemasaran produk di media sosial dan desain packaging yang lebih menarik. Tujuannya untuk menambah pengetahuan mitra tentang bagaimana memasarkan produk dimasa pandemi, dan meningkatkan daya beli konsumen dengan packaging yang lebih menarik

4) Membuat sistem pembukuan sederhana

Membuat laporan keuangan sederhana yang bertujuan memberikan wawasan kepada kelompok tani, ibu-ibu PKK, dan pemilik usaha lainnya agar lebih faham mengenai pentingnya pembukuan (laporan keuangan) untuk usahanya.

\section{Teknik Pengumpulan dan Analisis Data}

Data yang digunakan dalam penelitian ini adalah data kualitatif. Untuk mendukung keperluan analisis data dalam penelitian ini, maka pengumpulan data dilakukan dalam metode studi kasus dari beberapa sampel yang berhubungan untuk dipelajari. Metode ini digunakan untuk memperoleh data-data yang berkaitan dengan penelitian. Analisis data dengan melakukan tahap pengolahan data dan memeriksa kelengkapan data, dan melakukan analisis serta penafsiran data yang sudah diperoleh.

\section{HASIL DAN PEMBAHASAN}

Kegiatan pembuatan selai dilakukan pada minggu kedua tanggal 7 September 2021, di posko KKN 13 A Luar Kota, yang dihadiri oleh ibu-ibu Kelompok Tani Nanas Desa Pagaruyung. Kegiatan diawali dengan melakukan sosialisasi tentang pengolahan buah nanas menjadi berbagai macam produk yaitu berupa selai nanas, sirup nanas, dan puding nanas. Selanjutnya dilakukan demonstrasi produk yang disebarkan melalui grup WhatsApp untuk memudahkan pemahaman tentang pengolahan nanas.

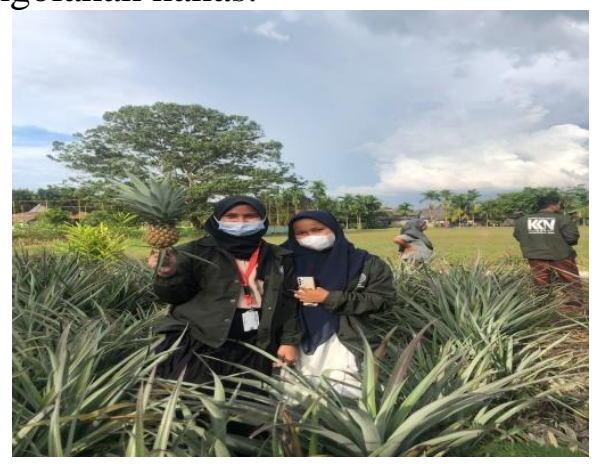

Gambar 1. Pemilihan buah nanas

Selanjutnya memproduksi buah nanas menjadi produk yaitu berupa selai nanas, sirup nanas, dan puding nanas. Teknik produksi dilakukan dengan:

1. Pemilihan buah nanas

Buah nanas yang dipilih adalah nanas yang sudah tua atau matang

2. Pengupasan dan pemotongan nanas

Buah nanas dikupas hingga bersih lalu dipotong-potong ukuran kecil

3. Penghancuran nanas

Buah nanas dihancurakan menggunakan mesin blender

4. Pemisahan sari nanas dan ampasnya Nanas yang sudah diblender di saring, tetapi jangan diperas terlalu kering

5. Masak selai nanas

Nanas yang sudah disaring dimasak menggunakan wajan dengan campuran bahan gula pasir, dan kayu manis agar selainya tidak terlalu asam. Lalu diaduk hingga matang sampai warna berubah menjadi kuning keemasan dan mengental.

6. Masak sirup nanas

Air perasan nanas (sari nanas) dimasak menggunakan wajan dengan tambahan gula pasir agar tidak terlalu asam. Lalu diaduk hingga mendidih

7. Masak pudding nanas

Nanas yang sudah diblender dimasak menggunakan wajan dengan tambahan bahan-bahan. Yaitu agaragar, gula pasir, air, garam, dan vanili. Kemudian diaduk hingga mendidih, 
setelah mendidih masukan kedalam kotak dan diamkan hingga mengeras, setelah itu masukan kedalam lemari pendingin.

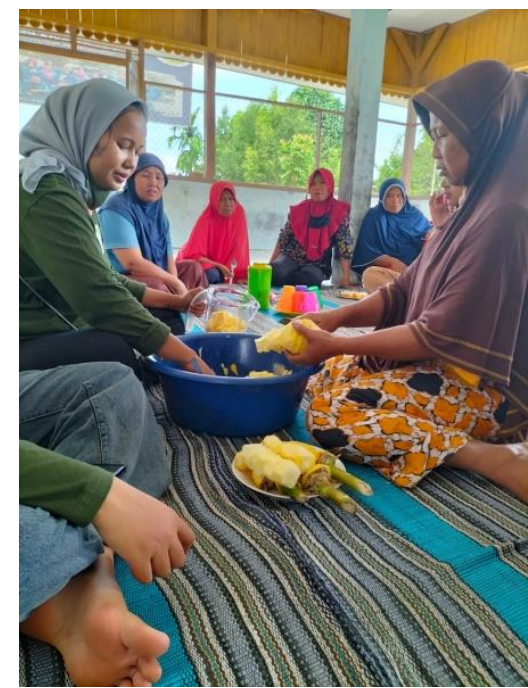

Gambar 2. Mengolah nanas

\section{Manajemen Pemasaran dan kemasan produk}

Kegiatan pengemasan produk dilakukan setelah kegiatan pengolahan nanas. Kemasan produk di desain oleh mahasiswa KKN kelompok 13 A Luar Kota. Kemasan selai nanas, dan puding menggunakan kotak, sedangkan sirup menggunakan botol dengan tampilan yang menarik menggunakan brand Kelompok Tani Nanas di kotak dan botol. Selanjutnya manajemen pemasaran, dilakukan dengan sosialisasi pemasaran via media sosial, terlebih dahulu anggota Kelompok Tani Nanas diajarkan tentang cara mengambil gambar produk yang pas dan menarik. Kegiatan ini penting untuk mendukung pelatihan pemasaran via media sosial karena objek yang akan digunakan adalah foto. Materi pemasaran pertama adalah via instagram. Instagram merupakan sosial media yang banyak digunakan, yang muncul belum lama namun mampu membumi di tengah tenarnya facebook maupun twitter. Sosialisasi pemasaran produk via instagram membahas tentang cara membuat instastory, cara upload foto produk, cara menandai orang dan menambahkan TAGAR (Tanda Pagar) serta memfollow banyak akun instagram dari masyarakat yang terjangkau agar produk yang dipasarkan dapat dilihat dan dikenal oleh banyak orang. Materi pemasaran selanjutnya adalah via Shoopee atau web lainnya. Shopee merupakan salah satu situs belanja online yang cukup booming. Shopee memungkinkan untuk menjangkau pembeli yang lebih luas. Pelatihan diisi dengan tata cara untuk membuka toko via Shoope, kemudian mengupload produk serta mengisi kelengkapan penjualan produk via Shoopee seperti jasa pengiriman, nomor telepon yang dapat dihubungi, sampai menambahkan nomor rekening.

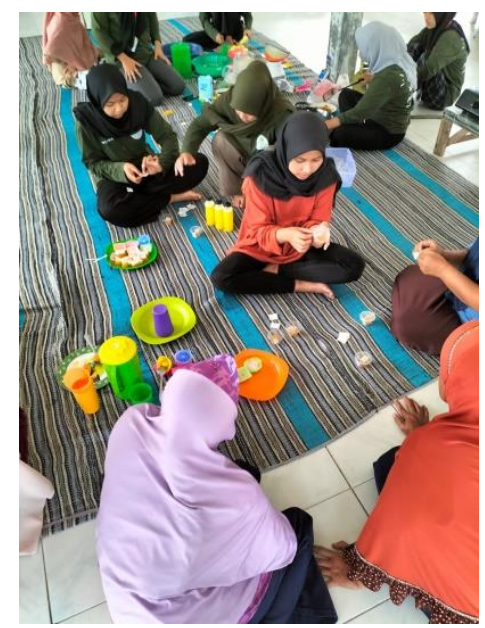

Gambar 3. Packaging produk

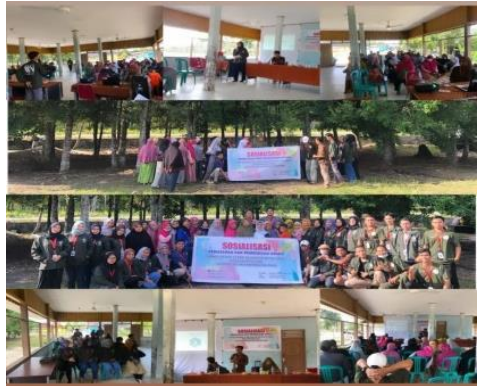

Gambar 4. Sosialisasi pemasaran

\section{Pengolahan limbah nanas menjadi pupuk}

Kegiatan pengolahan limbah nanas merupakan kegiatan pemanfaatan limbah hasil produksi produk olahan nanas tadi yang kemudian dibuat menjadi pupuk cair yang bermanfaat untuk tanaman. Selain 
olahan buah, nanas memiliki banyak potensi lain yang bisa diolah lebih lanjut menjadi produk bernilai jual tinggi. (Aisyah, dkk, (2019: 60). Pengolahan limbah nanas ini bertujuan untuk mengurangi limbah yang dapat merusak lingkungan, menambah nilai jual limbah kulit nanas. Menurut Muhammad Jusfar, dkk, (2019: 135) Kulit nanas merupakan limbah organik hasil sisa pembuangan produksi buah nanas yang mengandung beberapa senyawa yang dapat dijadikan produk olahan bermanfaat. Berdasarkan kandungan nutrisinya, kulit nanas dapat dijadikan sebagai bahan pembuatan pupuk organikPupuk cair yang dihasilkan dari limbah kulit nanas juga dapat menyediakan unsur hara bagi tanaman sehingga dapat mengurangi penggunaan pupuk kimia yang harganya relatif mahal serta dapat mencegah tanaman terserang patogen penyebab penyakit tanaman. Pengolahan limbah nanas dilakukan bersama dengan anggota kelompok tani nanas dan anggota karang taruna di posko KKN kelompok 13A Luar Kota. Pembuatan pupuk menggunakan bahan dasar yaitu kulit nanas, dan tambahan EM4, gula merah, dan air cucian beras. Kulit nanas hancurkan menggunakan blender dengan tambahan air cucian beras, setelah halus kemudian disaring dan diperas airnya, kemudian dimasukan kedalam botol berukuran 1,5 liter dengan takaran isi sebanyak banyak 1 liter, kemudian campur EM4 dengan takaran $100 \mathrm{ml}$, dan gula merah yang sudah dicairkan sebanyak $100 \mathrm{ml}$. Semua bahan dicampur hingga merata, kemudian didiamkan selama 10 hari, dalam proses pendiaman, tutup botol pupuk cair dibuka 2 hari sekali. Setelah proses pendiaman pupuk cair dapat diaplikasikan dengan cara penyemprotan ke daun tanaman

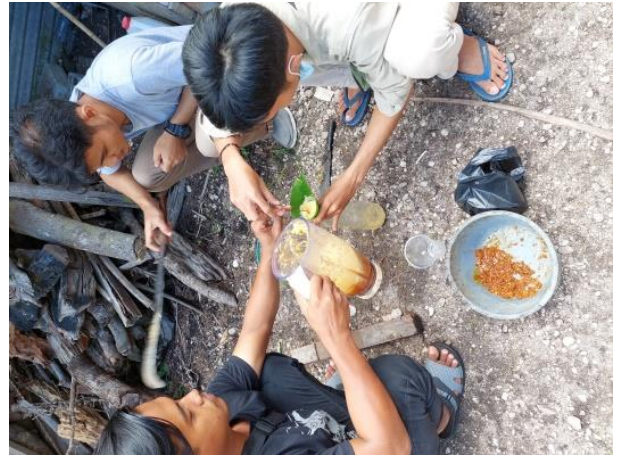

Gambar 5. Pembuatan pupuk cair

\section{Pembukuan sederhana usaha}

Kegiatan pembukuan dilakukan pada minggu ke empat. Kegiatan diawali dengan melakukan sosialisasi pembukuan sederhana. Penyampaian materi dilakukan oleh mahasiswa KKN kelompok 13A Luar Kota. Kegiatan ini bertujuan untuk menambah wawasan Kelompok Tani Nanas dan membuat pembukuan usaha olahan nanas. Dimana sebelumnya di Desa Pagaruyung ini masih banyak yang tidak menggunakan pembukuan dalam usaha karena kurangnya pengetahuan. Oleh sebab itu dilakukan sosialisasi pembukuan. Materi yang disamapaikan yaitu tentang pentingnya pembukuan dalam usaha beserta bagaimana cara membuat pembukuan sederhana. Pelatihan dilakukan dengan cara praktek langsung, dengan menghitung berapa modal yang dihabiskan untuk produksi olahan nanas yang telah dilakukan. Lalu kemudian dibuatkan templete untuk pemubukuannya untuk memudahkan anggota Kelompok Tani Nanas.

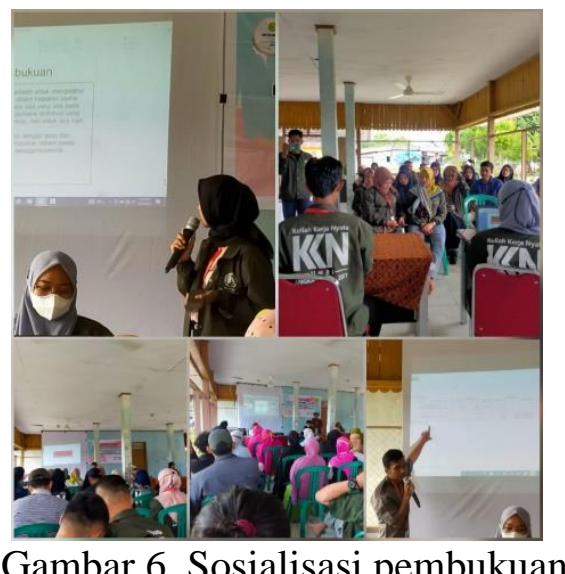

Gambar 6. Sosialisasi pembukuan 


\section{SIMPULAN}

Kegiatan pengabdian yang dilaksanakan melewati 4 tahap kegiatan, yaitu pelatihan pembuatan produk olahan nanas, pemasaran dan kemasan produk, pembuatan pupuk cair dari limbah nanas, dan pembukuan sederhana. Pembuatan produk nenas diawali dengan kegiatan survey dan pembuatan video teknik pemilihan buah nanas yang baik untuk diolah selanjutnya dilakukan proses pengupasan, penghalusan, pemasakan dan penyimpanan. Kegiatan pembuatan pupuk cair limbah nanas dilaksanakan dengan memanfaatkan limbah diantaranya adalah limbah kulit nanas, air cucian beras, gula merah, EM4 yang kemudian difermentasi selama 10 hari. Kegiatan sosialisasi dilaksanakan dengan menggunakan metode presentasi dan diskusi interaktif yang memuat semua pertanyaan dan respon positif dari para tamu atau pendengar.

\section{UCAPAN TERIMAKASIH}

Penulis mengucapkan terima kasih kepada Lembaga Penelitian dan Pengabdian Masyarakat Universitas Muhammadiyah Riau, sebagai pelaksanana kegiatan KKN UMRI Dari Desa Untuk Negri. Dan terimaksih kepada masyarakat Desa Pagaruyung telah menerima kelompok KKN 13A luar kota melaksanakan pengabdian di Desa Pagaruyung, Kecamatan Tapung, Kabupaten Kampar, Provinsi Riau.

\section{DAFTAR PUSTAKA}

[1]. Tri Lestari1, E. D. (2020). Optimalisasi Sistem Produksi Produk Olahan Nenas. Jurnal Pengabdian kepada Masyarakat UBB Vol. 7 No.2, 53-61.

[2]. Silitonga, H. V. (2018). Analisis Nilai Tambah Pengolahan Nanas Menjadi Keripik dan Sirup (Studi Kasus: Desa Sipultak, Kec. Pangaran, Kab.
Tapanuli Utara.) Skripsi. Sumatra Utara: Universitas Sumatra Utara.

[3]. Ramadhani, A. H. Reny, R. Riska, S. (2019). Inisiasi Pengolahan Nanas Terpadu Sebagai Upaya Peningkatan Nilai Jual Sumber Daya Lokal Dusun Puherjo Kabupaten Kediri. Prosiding Seminar SIMBIOSIS, Vol 4, 59-63

[4]. Simanjuntak, M. A. Hasibuan, S. Maimunah. (2019). Efektifitas Penggunaan Bokashi Blotong Tebu dan Pemberian Pupuk Organik Cair Kulit Nanas Terhadap Produktifitas Tanaman Kecipir (Psophocarpus tetragonolobus L.). Jurnal Ilmiah Pertanian (JIPERTA), 1(2), 133-143. 